\title{
2019 Award for an Exemplary Program or Achievement in a Mathematics Department
}

The Department of Mathematics and Computing at Franklin College is the recipient of the 2019 AMS Award for an Exemplary Program or Achievement in a Mathematics Department.

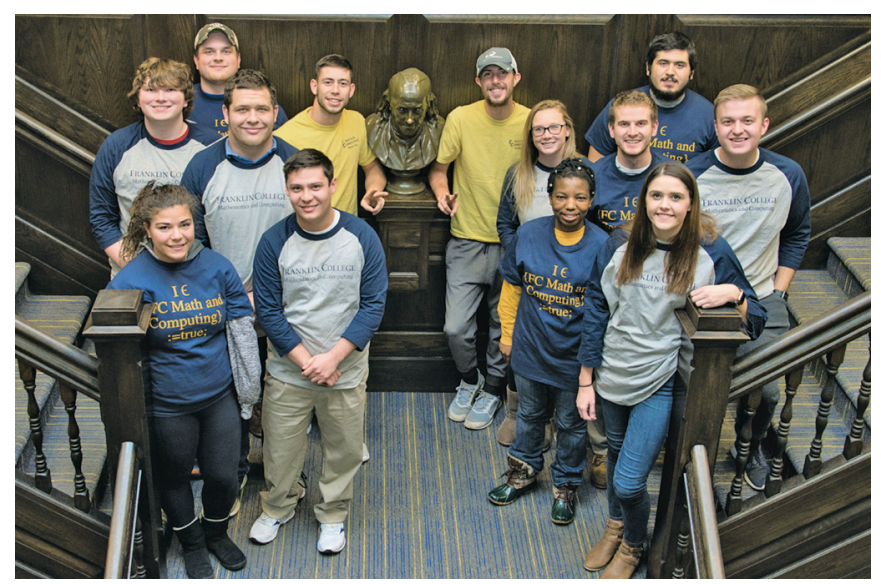

Franklin College's 2019 senior mathematics majors.

\section{Citation}

The American Mathematical Society is pleased to announce that the 2019 Award for an Exemplary Program or Achievement in a Mathematics Department goes to the Department of Mathematics and Computing of Franklin College in Franklin, Indiana, for its outstanding achievements in the undergraduate mathematics program.

The comprehensive undergraduate program offered at Franklin College has unique curricular and co-curricular aspects. Their program, which considers the student holistically, is intentional, carefully planned, and regularly assessed and revised. Their model can and has been disseminated to other institutions. For example, a minicourse based on the Franklin College model, "Creating a Purposeful Student Learning Experience," was presented

For permission to reprint this article, please contact: reprint -permission@ams.org.

DOI: https://dx.doi.org/10.1090/noti 1865 at MathFest in 2016 and 2017. The Franklin Curriculum is designed around the following principles:

1) Research-based, all-inclusive goals and objectives

2) Scaffolded developmental strands

3) Engaging department culture

4) Innovative curriculum

5) Deliberate integration of co-curricular experiences

6) Comprehensive assessment

In addition to having well-defined programmatic goals, the goals and objectives for students are clear and comprehensive; the department is in the process of implementing online individual experiential portfolios to assist students in collecting, organizing, and reflecting on artifacts documenting their achievements. This integrated and engaging learning experience for mathematics students results in large numbers of majors highly involved in math-related activities during college and extremely successful professionally after graduation.

Their approach to developing career-readiness skills is well thought out and effective. All department instructors ensure that their students can work effectively in a team, solve complex problems, and communicate effectively both orally and in writing with a variety of audiences within and outside of mathematics. The department also brilliantly leverages the knowledge and experience of the older students to teach younger students. Older students with internship or workplace experience meet with younger students so that they can ask questions and learn about these opportunities. The older students learn to articulate how these experiences influenced them, a helpful skill to have for future job interviews, something the department is very aware of. This intermingling of students from different years is replicated in the department's extracurricular and social activities. Engagement with alumni is another im- 


\section{FROM THE AMS SECRETARY}

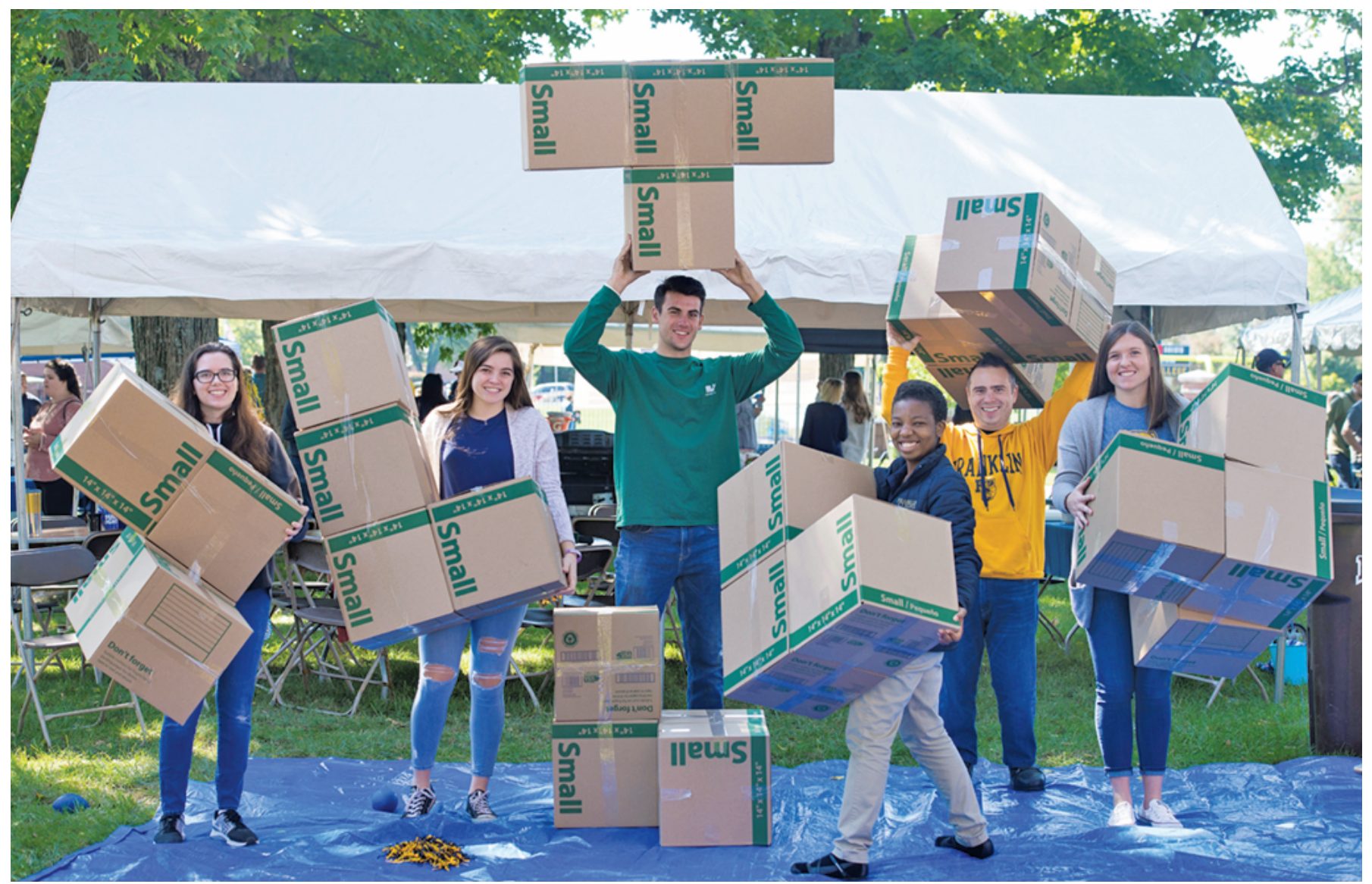

Students engaged in SOMA activity with faculty member at departmental Homecoming tent.

portant pillar of the department's strategy. The department asks alumni what they learned during their four years that is actually helpful in the workplace. This allows instructors to further tailor their approach. Informal events permit current students to mingle with alumni. Students participate in "Shadow Day" each semester, to get firsthand experience in a workplace.

Franklin College's Department of Mathematics and Computing has made a sustained and imaginative effort over several years to create an inspiring culture of collaboration and excellence for their students. That culture has fostered an admirable level of academic and professional success for its students and alumni.

Thus we are delighted to present the 2019 AMS Award for an Exemplary Program to the Department of Mathematics and Computing at Franklin College.

\section{About the Program}

In 2019, Franklin College will launch a year-long celebration of "A Legacy of Mathematics." The triggering achievement is the fact that three mathematics faculty members-Dwight Heath (1919-1961), Richard Park (1958-2003), and Daniel Callon (1987-today) - collectively have spanned a century at the college. But the larger focus is the culture of creative, integrated, experiential curricular and co-curricular learning that has been carefully nurtured by the combined efforts of the faculty, students, alumni, community partners, and donors. This program has been cited by the Association of College and University Educators as a national model of twenty-first-century career skill preparation.

A carefully scaffolded curriculum features innovative courses at all levels that incorporate technology and the development of professional skills and dispositions, including an emphasis on written and oral communication and collaborating effectively in formal and informal team environments. Annual co-curricular programming averages 200 distinct participants on a campus of 1,000 students, with each student involved in an average of four individual activities. Capstone experiences include internships, independent research projects, team statistical consulting projects for local nonprofit organizations, and alumni-coached team projects to analyze big data sets.

The foundations of this current program have been under development for over thirty years, building on funding from the National Science Foundation and Lilly Endowment Inc. to acquire technological infrastructure and to write curricular materials, resulting in selection as one of 


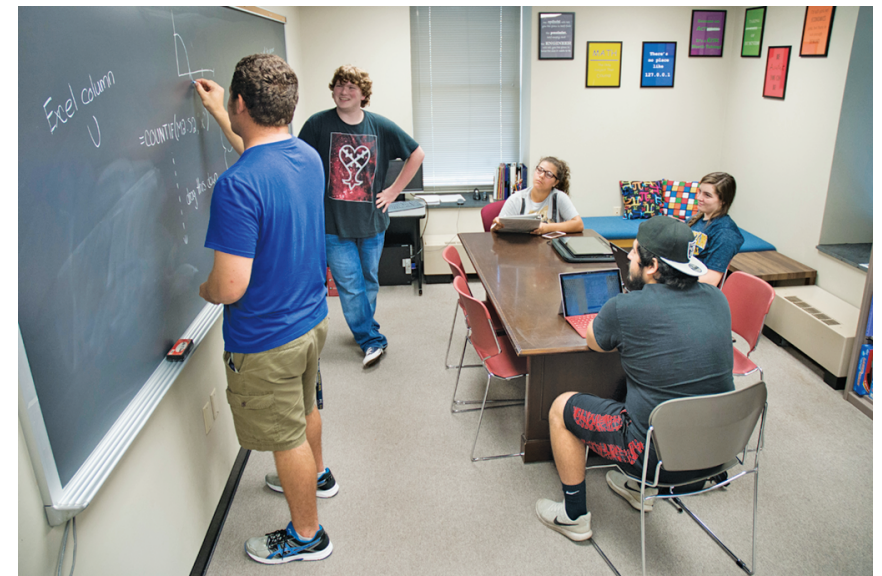

Students work collaboratively on a project in student resource room.

EDUCOM's 101 Success Stories of Information Technology in Teaching and Learning in Higher Education in 1993. A student learning plan based on principles of active learning was developed in 1995; a major component of the associated comprehensive assessment program was featured in Assessment Practices in Undergraduate Mathematics (MAA Notes 49) in 1999. Departmental hiring procedures have emphasized the department's philosophy of experiential learning and involvement in curricular and co-curricular programming for over two decades. The institution of weekly lunches including all mathematics faculty in 2009 has fostered communication and solidified departmental unity, resulting in a program graduating an average of twelve mathematics majors and six minors per year.

\section{About the Award}

The Award for an Exemplary Program or Achievement in a Mathematics Department was established by the AMS Council in 2004 and was given for the first time in 2006.

This award recognizes a department that has distinguished itself by undertaking an unusual or particularly effective program of value to the mathematics community, internally or in relation to the rest of society. Departments of mathematical sciences in North America that offer at least a bachelor's degree in mathematical sciences are eligible. Through the generous support of an anonymous donor, the award carries a cash prize of US $\$ 5,000$. The award is presented by the AMS Council acting on the recommendation of a selection committee. The members of the 2019 selection committee were Craig Evans, Rhonda Hughes, Brea Ratliff, Cristoph Thiele, and Sylvia Wiegand (chair).

Credits

Article photos by Renee Kean.
A list of previous recipients of the Award for an Exemplary Program or Achievement in a Mathematics Department may be found on the AMS website at www . ams.org/department-award.

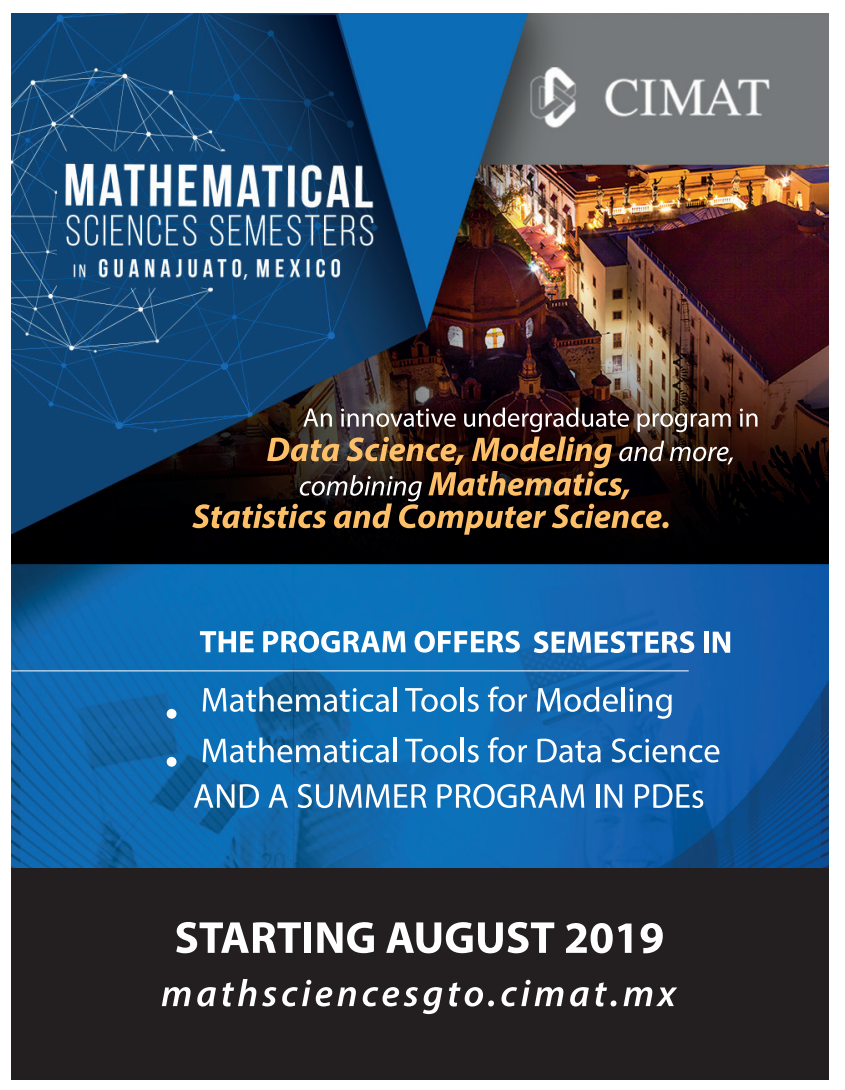

